\title{
Na literatura, a nossa memória: contribuindo para a construção da identidade e perpetuação da cultura dos educandos
}

\author{
Fabiana Ferreira Santos Miranda \\ UFU - Uberlândia, MG \\ Paula da Silva Lisbôa \\ UNIPAM - Patos de Minas, MG
}

\begin{abstract}
Resumo
A memória, mais do que um mecanismo biológico e individual, representa um processo relacionado à natureza social do homem. Entendida como possibilidade de se revisitar o passado, permite relembrar e recriar acontecimentos com as percepções presentes. A Literatura por sua vez, pode ser reconhecida como uma manifestação artística por meio da qual os seres humanos encontram prazer, se reconhecem, promovem reflexões, e se eternizam. Com base no exposto, ressaltase a existência de uma relação entre Memória e Literatura. As histórias trazidas pela memória propiciam o gosto pela leitura e produção literária na mesma proporção em que a Literatura serve também à memória, já que possui o poder de imortalizar os espaços, os tempos e as lembranças. Desse modo, a Literatura pode ser reconhecida como meio privilegiado para a apreensão de aspectos da constituição da memória coletiva. Buscando estabelecer relações entre Literatura e Memória, faremos o relato de uma experiência vivenciada pela equipe de educadores e alunos da E. M. Cônego Getúlio, do Distrito de Pilar, Município de Patos de Minas - MG. O trabalho desenvolvido teve por objetivo contribuir para a construção da identidade e valorização da cultura local, a partir de um levantamento de histórias da região e da prática de produção de textos.
\end{abstract}

Palavras-chave: cultura; identidade; literatura; língua portuguesa; memória.

\begin{abstract}
More than a biological and individual mechanism, memory represents a process related to the social nature of human beings. Understood as the possibility of revisiting the past, memory allows us to recall and recreate events with perceptions in the present. Literature, in turn, can be recognized as an artistic expression through which human beings find pleasure, self-knowledge, reflection and immortalization. In light of this, the relationship between memory and literature is highlighted in this paper. The stories in our memory provide a taste for reading and literary production in the same proportion in which literature serves memory, for it has the power to immortalize spaces, times and memories. Hence, literature can be seen as a preferred means for understanding aspects regarding the constitution of collective memory. With the objective of establishing relationships between literature and memory, this article reports the experience of educators and students at Cônego Getúlio Municipal School, in the district of Pilar, municipality of Patos de Minas, Brazil. The study aimed at contributing to the construction of identity and valorization of local culture based on a collection of the region's history as well as the practice of text production.
\end{abstract}

Keywords: culture, identity, literature, portuguese language, memory. 


\section{INTRODUÇÃO}

Tendo como subsídio as reflexões e os estudos propostos pela formação continuada de educadores da Rede Municipal de Educação de Patos de Minas, buscamos continuamente a construção de um fazer pedagógico diferenciado, que, por meio das metodologias e práticas ligadas ao ensino de Língua Portuguesa, pudesse favorecer aprendizagens significativas, condizentes com as dificuldades diagnosticadas.

Em 2008, foi observada na E. M. Cônego Getúlio a necessidade de ações que pudessem contribuir para a construção da identidade dos alunos e valorização da cultura do Distrito de Pilar, já que os estudantes se referiam negativamente ao lugar e aos seus moradores, tendo poucas perspectivas em relação ao futuro. $O$ trabalho foi desenvolvido do $6^{0}$ ao $9^{\circ}$ ano do Ensino Fundamental, e organizado pela professora das disciplinas Língua Portuguesa e Artes, que incorporou ao seu planejamento as sugestões dos cadernos das Olimpíadas de Língua Portuguesa ${ }^{1}$, material estruturado em oficinas, com propostas de produção textual para os gêneros Poesia e Memória, tendo como temática o lugar onde se vive.Assim, mesclando-se Literatura e Memória, buscou-se o desenvolvimento de capacidades de linguagem relacionadas à produção textual, e um favorecimento de reflexões sobre a memória da comunidade, contribuindo para a construção da identidade e valorização da cultura local. Os resultados conquistados extrapolaram a participação das classes nas Olimpíadas de Língua Portuguesa ou ainda a prática rotineira do ensino de língua materna, culminando em significação e aprendizagem.

\section{CONSIDERAÇÕES TEÓRICAS}

Pensar no conceito de memória - e em sua importância para a construção da própria história - é pensar na possibilidade de se visitar um passado que não mais existe, estando este, mesclado por percepções distintas. Sendo assim, “com a evocação da memória, o passado torna-se acessível ao homem, onde estão alojadas as lembranças e as esperanças.” (Diehl, 2002, p. 122). Nesse contexto, o tempo, que não pode ser detido na realidade concreta e efêmera, se rende à força da memória: “[...] essa memória ressurrecionista, evocadora, uma

\footnotetext{
${ }^{1}$ O Programa Olimpíadas de Língua Portuguesa é realizado pelo MEC e pela Fundação Itaú Social, com coordenação técnica do CENPEC. Desenvolve ações de formação de professores, com o objetivo de contribuir para a ampliação do conhecimento e aprimoramento do ensino da escrita. Uma das estratégias é a realização de um concurso de produção de textos que premia poemas, memórias literárias, crônicas e artigos de opinião elaborados por alunos de escolas públicas de todo o país.
} 
memória que diz a cada coisa 'Lázaro, levanta-te.’” (Cagnebin, 1997, p. 147). A memória é, então, o que salva o passado do esquecimento, ressaltando-se ainda que o ato de recordar transcende o de ressuscitá-lo, ganhando sublimidade à medida que o recria e o reconstrói com as percepções do presente. Cabe lembrar que as lembranças também não são originais, já que são oriundas de conversas e de interações com outras pessoas em uma relação recíproca. Dessa maneira, “[...] lembrar não é reviver, mas refazer, reconstituir e repensar com imagens de hoje, as experiências do passado.” (Bosi, 2003, p.55).

Apresentada uma breve exposição sobre a memória, é importante tecer considerações sobre a literatura, manifestação artística por meio da qual os seres humanos encontram prazer e deleite, se reconhecem, promovem reflexões redimensionando suas ações, e acima de tudo se eternizam. A literatura é uma promessa de imortalidade já que salva os autores do esquecimento, permitindo a permanência e continuidade das histórias, que proporcionam explicações que, emersas na fantasia, acalmam as inquietações dos seres humanos.

Diante do relevante papel da literatura enquanto propiciadora de transcendência à condição humana, é possível pensar em um entrelaçar entre memória e a literatura como uma relação consistente e significativa. Metaforicamente, como em uma via de mão dupla, a memória serve à literatura bem como a literatura serve à memória. Em uma primeira aproximação é possível perceber o quanto as lembranças, lendas e casos aguçam o interesse das crianças. Além do gosto pela leitura, há o gosto pela escrita. De acordo com Scliar (2007, p. 08), sua aproximação com a arte de escrever começa com as histórias que ouvia dos pais, dos parentes, dos vizinhos: “[...] Comecei cedo; minhas recordações de infância estão ligadas a isso: ouvir e contar histórias.”

Na mesma proporção em que as histórias trazidas pela memória propiciam o gosto pela leitura e produção literária, a literatura serve também à memória, já que tem o poder de eternizar as histórias, os espaços, os tempos e as lembranças das pessoas, sendo assim as obras literárias, memórias sólidas de épocas, percepções e filosofias. Nesse sentido, entre as diversas fontes disponíveis a historiadores para o resgate da memória estão os livros. Baez (1975, p. 24) observa que “[...] o vínculo poderoso entre livro e memória faz com que um texto deva ser visto como peça-chave do patrimônio cultural de uma sociedade e, certamente, de toda a humanidade.”

Inseridas em um contexto marcado por diferentes transformações, as instituições escolares assumem cada vez mais a obrigatoriedade de oferecer um ensino pautado na formação para a reflexão/ação, tendo em vista a relevância de temas como a diversidade, multiculturalismo e inclusão. Para que haja o respeito à diversidade, é imprescindível um 
trabalho que venha incitar nos estudantes o estudo da própria cultura enquanto construtora de sua identidade, tendo pertinência o papel da memória para essa construção. Dessa maneira segundo os Parâmetros Curriculares Nacionais de História, “[a] memória é um elemento essencial do que se costuma chamar identidade [...] cuja busca é uma das atividades fundamentais dos indivíduos e das sociedades de hoje”. (Brasil, 1999, p. 476).

Diante do exposto, as instituições escolares devem assumir o compromisso de repensar suas ações, buscando na cultura local e no sentimento de pertença, importante base de valores em que os estudantes poderão se ancorar para construção paulatina de sua identidade. Com tal objetivo, os profissionais poderão lançar mão de metodologias diferenciadas que aproximem o sujeito de seu contexto sócio-cultural.

Tendo em vista as considerações acima é possível perceber, que, permeando esse processo tem-se a presença da palavra que oferece ao ser humano a possibilidade de construir sua história, identidade e cultura, contribuindo também para a construção das histórias, identidade e cultura alheias. De acordo com os Parâmetros Curriculares Nacionais de Língua Portuguesa (2001, p.49) “[...] o desenvolvimento da capacidade expressão oral do aluno depende consideravelmente de a escola constituir-se num ambiente que respeite e acolha a vez e a voz, a diferença e a diversidade.”

Com base no exposto, reforça-se o papel da escola como promotora de reflexões sobre as manifestações culturais, por meio da relação entre memória e a Literatura e também do trabalho com a linguagem, consolidando e valorizando a identidade que se constrói tanto na relação de pertença com as origens, como na relação de respeito ao outro em sua essência: ouvindo, entendendo e interagindo com seus valores, sua história, suas crenças e filosofias.

\section{RELATO DA EXPERIÊNCIA PEDAGÓGICA DA E. M. CÔNEGO GETÚLIO}

A experiência descrita a seguir foi desenvolvida na E. M. Cônego Getúlio, situada no distrito de Pilar, município de Patos de Minas, que atende a um público de alunos desse distrito e de comunidades rurais que o rodeiam, tendo atualmente cerca de 260 alunos matriculados na Educação Infantil e Ensino Fundamental. Ressalta-se que esse trabalho foi realizado com alunos dos anos finais do Ensino Fundamental, durante aulas das disciplinas de Língua Portuguesa e Artes.

O trabalho se iniciou pela observação das percepções dos alunos sobre o lugar onde moram. Foi diagnosticado um determinismo muito grande, segundo o qual os alunos não precisariam estudar, já que não teriam oportunidades, seriam piores e nunca concorreriam 
com alunos do meio urbano, não demonstrando, portanto, perspectivas de construção de uma vida mais digna e feliz. Não obstante, apresentavam desrespeito para com a comunidade, não conseguindo apontar pontos positivos com relação à mesma, focalizando em contrapartida, nas inúmeras desvantagens de habitá-la. Tais percepções eram bastante visíveis, já que se externavam em situações corriqueiras como falta de zelo, pois além de estes alunos não cuidarem do espaço de sala de aula, depredavam ambientes como banheiros e refeitórios.

É preciso considerar a pertinência da participação das classes nas Olimpíadas de Língua Portuguesa, pois o tema sugerido pelo concurso - o lugar em que vivo - vinha de encontro à necessidade diagnosticada. Seguindo os direcionamentos apresentados aos educadores que fizeram adesão ao programa, os gêneros textuais trabalhados foram Poesia ${ }^{2}$ e Memórias $^{3}$, tendo como procedimento metodológico a Sequência Didática ${ }^{4}$.

O primeiro passo foi a retomada de um projeto realizado no ano de 2004, na disciplina Língua Portuguesa, que consistiu na coleta de lendas e casos contados por pessoas da comunidade, textos que foram recontados pelos alunos e consolidados em um livro costumeiramente emprestado pela biblioteca.

Em seguida, foi feita a apresentação da proposta de trabalho aos alunos, que compartilharam da elaboração de um cronograma de atividades. Iniciou-se, então, o desenvolvimento de ações que integravam o material das Olimpíadas de Língua Portuguesa: atividades de sensibilização relacionadas aos gêneros textuais; leitura de textos representativos dos gêneros; estudo das características dos textos; atividades lúdicas e diversificadas, com foco na percepção e valorização da localidade e de seus moradores e produção de textos.

Quanto ao gênero textual Poesia, destacam-se as atividades: a confecção de murais; momentos de leitura; declamação de poemas; pesquisa poética com funcionários e alunos da escola; definição de conceitos sobre o gênero; construção de gráficos a partir de pesquisas relacionadas às leituras; realização do chá com poesia; estudo específico sobre rimas, metáforas, trovas, poesia de cordel, estrutura de poesias, recursos estilísticos; passeio poético

\footnotetext{
${ }^{2}$ Gênero textual trabalhado em Língua Portuguesa , no $6^{\circ}$ e $7^{\circ}$ ano, com material das Olimpíadas de Língua Portuguesa.

${ }^{3}$ Gênero textual trabalhado em Língua Portuguesa, no $8^{\circ}$ e $9^{\circ}$ ano, com material das Olimpíadas de Língua Portuguesa.

${ }^{4}$ A Sequência Didática é um conjunto de atividades organizadas de maneira sistemática para promover a aprendizagem específica de habilidades de linguagem com base em um gênero textual. Segundo Joaquim Dolz e Bernard Schneuwly (2007) a Sequência Didática é um procedimento que organiza o ensino e permite levar em conta, ao mesmo tempo e de maneira integrada, os conteúdos de ensino, os objetivos de aprendizagem e a necessidade de variar os suportes, as atividades e as dominantes das aulas (estudo linguístico, leitura, escrita, etc.).
} 
e o uso dos sentidos; sensibilização e reflexões sobre o lugar onde viviam; produção coletiva e individual de poesias; estudo dos parâmetros de revisão de textos; revisão e reescrita; listagem das habilidades adquiridas no processo.

Em relação ao gênero textual Memórias, foram trabalhadas as seguintes atividades: pesquisa e apresentação de lembranças relacionadas a objetos; interpretação e sensibilização para textos de memórias; estudo minucioso dos sinais de pontuação, marcadores temporais, diferenciação de impressão e descrição, diferenciação no uso dos verbos do passado (pretérito perfeito e imperfeito); realização de entrevistas em sala e em casa feita com moradores da comunidade; interpretação e leitura de textos de memória; estudo dos parâmetros de correção de textos; produção de textos coletivos e individuais; revisão e reescrita; monitoramento das habilidades adquiridas.Além dos gêneros enfocados nas Olimpíadas de Língua Portuguesa trabalhou-se com uma coleta de fotografias que valorizassem a comunidade, sendo desenvolvidas as seguintes atividades: estudo sobre fotografia e suas diferentes funções; a expressividade na fotografia; levantamento de lugares, objetos e pessoas a serem fotografados; passeio fotográfico; montagem de apresentação em Powerpoint unindo fotografias e poemas para serem apresentados nas salas.

Os textos e fotografias dos alunos foram editados e publicados no livro Na Literatura, a Nossa Memória, que pode ser considerado o resultado consolidado do trabalho vivenciado. A primeira seção do livro, intitulada "Casos e lendas da região: os moradores como contadores de histórias”, traz textos recontados pelos alunos, com personagens lendárias e míticas e situações cotidianas da localidade:

\section{A história de Valdomiro de Paulo}

Entrevistada: Áurea Garcia Machado - 59 anos.

Recontado por: Tayrine F G.G.

$1^{\circ}$ Ano do $2^{\circ}$ Ciclo de 2004.

Antigamente, em Pilar, existiu um menino, que até os sete anos era uma criança normal. Depois dos sete anos ele começou a ficar diferente, principalmente quando chegava perto do córrego.

Passado algum tempo ele mudou para o córrego de uma vez por todas, tirou suas roupas e ficou nu. Ele só vinha para casa para dormir. Parou de falar, só pronunciava pouquíssimas palavras.

A notícia se espalhou. Pessoas de outras cidades passavam para conhecê-lo e traziam comida para ele, fazendo de tudo para que ele voltasse para casa. A mãe dele cuidava muito bem dele.

Algumas pessoas faziam votos de levar comida para esse homem.Traziam ele para cidade, compravam roupas e vestiam ele. Mas as vestes incomodavam . Ele tirava as roupas e voltava de novo para o córrego. Aqui em Pilar todos o conheceram. Valdomiro de Paulo que logo adoeceu e veio a falecer. 
(p. 19)Em seguida, na parte "Memórias: os moradores do lugar como protagonistas das narrativas” são apresentadas memórias literárias que revelam concepções de vida, pautadas na reflexão passado/presente, dos moradores do distrito:

\title{
O pouco que Deus me deu era o bastante
}

Entrevistado: José Marciano Gonçalves - Idade; 42 anos - Fazenda Cavaida Pilar - Patos de Minas. Autor: Franciele Cristina Gonçalves. $4^{\circ}$ Ano do $2^{\circ}$ Ciclo de 2008.

Em meados da década de setenta, eu e minha família morávamos na comunidade do Pântano - município de Coromandel - quando essa região ainda era quase deserta. Nesse lugar passei a maior parte da minha infância.

Por esses e outros motivos, aquelas terras que hoje são cercadas por grandes lavouras cafeeiras, ma trazem lembranças e memórias de uma vida sofrida e simples, mas também de uma vida feliz em que a união e o amor ao próximo ainda existia no coração de cada um de nós.

Pela condição financeira difícil de minha família, tive que trabalhar desde os cinco anos de idade. Meu pai, mesmo com doença de chagas, trabalhava como lavrador; minha mãe lavava roupas; eu e meus irmãos - os que já tinham idade apanhávamos feijão e trabalhávamos na capina de campos para ajudar na renda familiar.

Nessa época minha vida era muito diferente da de hoje. Na minha casa não havia televisão nem geladeira, pois a energia elétrica não havia chegado naquele lugar. A maior tecnologia que havia em minha casa era um velho rádio à pilha, que levava a alegria e despertava a imaginação das crianças.

Já que meus pais não tinham como comprar roupas, nós usávamos roupas que ganhávamos de outras pessoas, as quais iam passando de irmão para irmão. Quando raramente sobrava dinheiro, meus pais compravam o quichute, um sapato que era parecido com um chuteira, sendo de borracha.

Apesar de tanta desigualdade, tenho saudades dessa época, pois pequenas coisas faziam a diferença, não nos iludíamos com o que não podíamos ter. O pouco era o bastante...

Na terceira seção, "Escritores da comunidade: os moradores como produtores de textos diversificados” são publicados os textos produzidos por pessoas da comunidade e coletados pelos alunos, apresentando os moradores como poetas da comunidade:

\author{
Minha história \\ Vânia Lúcia de Sousa \\ Mãe da aluna Adriana do $7^{\circ}$ ano \\ $[\ldots]$ \\ Papai era um menino pobre \\ Trabalhava de peão \\ Conquistou o amor de todos \\ E o da filha do patrão
}


Mas o danado do velho

Proibiu aquele amor

Minha filha é menina rica

Não insista, por favor

[...]

E continuou trabalhando

Com muita dedicação

Até que um dia conheceu

Uma empregada do patrão

E com a menina pobre

Ele um dia se casou

Com trabalho e muita luta

Sua família formou

E tiveram cinco filhos

Era uma escadinha

Eram quatro rapazinhos

E também uma menininha

Mas Deus, que escreve certo

Sempre por linhas tortas

Veio a notícia, um dia

Sua esposa estava morta

E papai ficou viúvo

Com cinco filhos nos braços

Éramos tão pequeninos

Que em seu colo não havia espaço

$[\ldots]$

Mas um dia ele encontrou

Com a filha do patrão

Que ainda estava solteira

E ele abriu seu coração

Fomos obrigados um dia

O nosso amor renunciar

Mas se ainda estiver disposta

Quero contigo casar

A moça estava tremendo

E desse jeito respondeu

Não tem nada que me impeça

De criar os filhos seus

Somos hoje uma família

E mais três irmãos ganhei

Crescemos ao lado deles

E da madrasta que amei

$[\ldots]$ 
Na quarta parte, "Poemas: o olhar dos alunos para o lugar onde moram”, o livro apresenta os poemas produzidos pelos alunos, diante da visão dos mesmos sobre o lugar onde viviam:

\author{
Pilar: um lugar especial \\ Ácsa dos Santos Davi \\ $1^{\circ}$ Ano do $2^{\circ}$ Ciclo - 2008 \\ Aqui se localiza o Pilar \\ Um lugar em que se ouve pássaros a cantar \\ Onde moro, saio sempre a passear. \\ $\mathrm{E}$ com as lindas flores me encantar \\ Gosto muito de estar com minha família \\ Pois encontro harmonia \\ No meu lar há muita alegria \\ E a paisagem ajuda no dia-a-dia \\ $[\ldots]$ \\ Aqui tem muita amizade \\ Lugar de muitas felicidades \\ Onde não existe maldade \\ E a alegria em meu coração invade \\ O azul do céu é um véu \\ Que cobre este lugar \\ Em que tenho orgulho de morar.
}

(p. 76)

Por fim, a produção Na Literatura a Nossa Memória, trouxe uma seção denominada "Iconografia: fotos com legendas sobre os moradores, objetos antigos, paisagens do lugar...” com apresentação de objetos, paisagens, pessoas, casas, ou seja, de marcas que constituem a identidade dos moradores da comunidade de Pilar.

O lançamento do livro ocorreu na cerimônia de aniversário da escola, e contou com a participação dos poetas e contadores de histórias da comunidade. Esse foi um momento de magia e significação, que buscou na sabedoria do povo a possibilidade para a construção de novas aprendizagens. O projeto foi avaliado por toda a coletividade, buscando-se a elaboração de síntese para as aprendizagens conquistadas ao longo do processo.

\title{
CONSIDERAÇÕES FINAIS
}


Com base no relato apresentado é possível uma sistematização dos resultados, buscando-se um levantamento daqueles mais significativos. Por meio da proposição de um novo olhar para a comunidade na qual se vive, surgiu um otimismo que permitiu aos alunos, o desenvolvimento de um sentimento de pertença a essa comunidade, propiciando momentos de se ouvir os antigos moradores e suas memórias, valorizando-os enquanto contadores e construtores da própria história, encontrando verdadeiros poetas que buscavam na vida o fazer poesia. Por fim, o trabalho realizado permitiu aos estudantes envolvidos entender a importância da linguagem para a expressão de sentimentos e conquistas, despertando o sentimento de expectativa quanto ao futuro, que sem dúvida começa a ser tecido nas instituições escolares.

É imprescindível que se descreva também, as capacidades de linguagem desenvolvidas durante esse processo: habilidade de estruturar textos nos gêneros textuais trabalhados com coesão e coerência; uso adequado de metáforas e outros recursos estilísticos na busca da expressividade; declamar poemas com entonação; usar adequadamente mecanismos da língua (verbos, marcadores temporais, rimas, dentre outros); reconhecer parâmetros de revisão de textos buscando clareza e efeito estético.

Tem-se como resultado concreto, a produção coletiva do livro Na Literatura, Nossa Memória, o qual registra a significação de práticas pedagógicas que, pautadas na simplicidade, fazem a diferença na formação acadêmica, cultural e cidadã dos alunos.

\section{REFERÊNCIAS}

Baez F. (1975). História sem data. Rio de Janeiro: Civilização Brasileira.

BRASIL. S. E. F. (1999) Parâmetros Curriculares Nacionais: História e Geografia. Brasília: Ministério da Educação.

BRASIL S. E. F. (2001). Parâmetros Curriculares Nacionais: Língua Portuguesa. Brasília: Ministério da Educação.

Bosi, E. (2003) Memória e Sociedade: lembrança de velhos. São Paulo: Cia das Letras.

Cagnebin, J. M. (1997). Sete aulas sobre linguagem memória e história. Rio de Janeiro: Imago.

CENPEC (coord. técnica). (2008). Olimpíadas de Língua Portuguesa: escrevendo o futuro. Caderno do Professor. Orientação para produção de textos. Brasília: MEC. 
Diehl, A. A. (2002). Cultura historiográfica: Memória, identidade e representação. Bauru, São Paulo: EDUSG. (Coleção História).

Scliar, M. (2007). O Texto, ou: A Vida - Uma Trajetória Literária. Rio de Janeiro: Bertrand Brasil.

Schnewly, B.; Dolz, J. e colaboradores (2007). Gêneros orais e escritos na escola. Trad. e org. Roxane Rojo e Glaís Sales Cordeiro. Campinas: Mercado das Letras.

\section{AS AUTORAS}

Fabiana Ferreira Santos Miranda possui graduação em Letras e especialização em Língua Portuguesa pelo Centro Universitário de Patos de Minas. É mestre em Teoria Literária pela Universidade Federal de Uberlândia. Atualmente desenvolve atividades como Professora Formadora em instituições diversas.

e-mail: fabiana_fsm@yahoo.com.br

Paula da Silva Lisbôa possui graduação em Letras e especialização em Teoria Literária pelo Centro Universitário de Patos de Minas, sendo concluinte da especialização em Educação Especial pela UFSM. Atualmente, é diretora de escola na Rede Municipal de Ensino de Patos de Minas. Atua, ainda, como Professora Formadora, ministrando cursos em instituições diversas.

e-mail: p.s.lisboa@hotmail.com 